\title{
Existential Psychotherapies: Similarities and Differences among the Main Branches
}

\begin{abstract}
Authors agree that a range of different existential therapies exist. However, not much has been written about what is characteristic and distinctive of each existential therapy and the few claims that have been made are mainly hypothetical. Practitioners from the four main branches of existential therapy were asked about the authors and texts that have most influenced their practice and the practices they considered most characteristic of existential therapy. From all over the world, 29 daseinsanalysts, 82 existential-humanistic, 573 existential-phenomenological and 303 logotherapy and/or existential analysis practitioners participated in this study. Data shows that the scope of influence of an author is pretty much limited to the branch he is related to and only a few authors, in particular Frankl and Yalom, influence practitioners from all four branches. Five themes of practice are shared among the main existential branches as the most characteristics of existential therapy, with phenomenological practices being the most shared theme: but the frequency each of these themes of practice differs significantly depending on respondents' training or affiliated branch. Data corroborates the idea of different existential therapies, with logotherapy and/or existential analysis being the most markedly different branch of them all.
\end{abstract}

\section{Keywords}

Existential therapy; existential psychotherapies; logotherapy; daseinsanalysis, existentialhumanistic; existential-phenomenological. 


\section{Existential Psychotherapies: Similarities and Differences among the Main Branches}

Among existential psychotherapists we find a general consensus that "there is really no one existential therapy" (Basescu, 1963, p. 588): rather, there are several distinct forms (Barnett \& Madison, 2012; Besora, 1994; Burston, 2003; Cooper, 2003, 2012; E. Craig, 2008; M. Craig, Vos, Cooper, \& Correia, 2015; Deurzen \& Adams, 2011; Halling \& Nill, 1995; Hoffman, 2007; Jacobsen, 2007; Mahrer, 1996; Norcross, 1987; Owen, 1994;

Schneider \& Krug, 2010; Teixeira, 2006; Walsh \& McElwain, 2002; Yalom, 1980). This is due to a range of factors, including the diversity of existential philosophies in which it is theoretically based, the lack of any single founder of the existential schools (Besora, 1994; Cooper, 2003; Halling \& Nill, 1995), and geographic and/or linguistic differences (Besora, 1994; E. Craig, 2008; Jacobsen, 2007).

Since the First World Congress for Existential Therapy, in May 2015, an e-mail debate has been ongoing between existential therapists from all over the world, to try to find a shared encompassing definition for existential therapy (Groth, 2015). Despite the efforts of several participants a unifying understanding between different existential therapies has not emerged (Groth, 2015).

To set the basis for a global definition of existential therapy, there is a need to clarify the differences and similarities across its different branches. However, there is little consensus on what separates and unifies the main existential therapies, and no empirical research has been conducted on this matter. The aim of this article, therefore, is to empirically explore similarities and differences across the branches.

\section{Which are the Main Existential Therapies?}


Excluding Erik Craig (2008), most authors have presented a similar taxonomy of the existential field. Daseinsanalysis is, consensually, agreed to be one of the branches of the existential approach. Logotherapy, existential-humanistic, and the British school of existential analysis are typically identified as three further branches of the existential field (Barnett \& Madison, 2012; Cooper, 2003, 2012; Cooper, Vos, \& Craig, 2011; M. Craig, et al., 2015; Deurzen \& Adams, 2011; Jacobsen, 2007). As the British school refers to a single country, some authors refer to it as part of the existential-phenomenological branch (Correia, Cooper, \& Berdondini, 2014; M. Craig, et al., 2015; Deurzen \& Adams, 2011): This is a broader concept that encompasses several schools and societies worldwide (Correia, et al., 2014), which stands at the same conceptual and international level as the daseinsanalysis, logotherapy and existential-humanistic concepts.

Several other schools of existential therapy are proposed by different authors: For instance, existential psychoanalysis (Besora, 1994), focusing (Barnett \& Madison, 2012), cognitive-existential and supportive-expressive therapy (Cooper, et al., 2011). However, none of these proposals are supported by more than one author.

\section{What Differentiates the Main Existential Therapies?}

Only a few authors (Besora, 1994; Cooper, 2003, 2012; E. Craig, 2008; M. Craig, et al., 2015; Norcross, 1987) compare the differences of the main existential schools.

Both Besora (1994) and E. Craig (2008) describe daseinsanalysis as phenomenological and obedient to European Continental philosophers, mainly Heidegger: It is concerned with the shared constitutional characteristics of human beings, rather than with the everyday phenomenal experience of the single client (E. Craig, 2008). Clients' problems are understood within a historical dimension and analysis of existence is made from an existential-hermeneutic stance (Besora, 1994). Cooper $(2003,2012)$ argues that 
daseinsanalysis is a more descriptive, psychological and individualizing approach, as compared with other existential therapies. He also suggests that it has a greater emphasis on viewing clients' difficulties from a pathologising perspective. Norcross (1987), based on a self-report questionnaire of therapeutic practices from 11 existential therapists associated to the daseinsanalytic approach, reported a greater use of psychoanalytic techniques, when compared with the 22 existential-humanistic therapists that were part of his sample.

Binswanger and Boss are frequently cited as daseinsanalysis' main influential authors (Besora, 1994; Cooper, 2003, 2012; Jacobsen, 2007).

The existential-humanistic approach, on the other hand, is seen as a more pragmatic and experiential existential therapy, mainly concerned with the ontic aspects and meanings of everyday life, as presented and lived by a particular client (E. Craig, 2008). In other words, it is seen as a therapy that focuses on the phenomenal experience of the here-and-now, and ignores the historical dimension of existence (Besora, 1994). It aims towards a personal growth, or transcendence; and Besora (1994) argues that it denies the human condition of facticity. Cooper $(2003,2012)$ describes it as an existential school that is interpretative (trying to identify underlying meanings), psychological (focus on emotional, cognitive and behavioural processes), individualized (focus on client's particular psychological process) and focusing on intrapersonal processes (problem emerges from client's psyche). Norcross (1987) reported a greater use of physical contact and Rogerian skills, when compared with their daseinsanalyst counterparts. The main influential authors are identified as May, Yalom, Bugental (Besora, 1994; Cooper, 2003, 2012; M. Craig, et al., 2015) and Schneider (Cooper, 2003; M. Craig, et al., 2015).

Both Cooper (2003, 2012) and Craig et al. (2015) describe the British school as having a focus on the client's relation to their world (inter-worldly). Its practice is based on a non-pathologising, non-directive, spontaneous (non-technique-based) and descriptive 
perspective. Depending on the author influencing the practice, British existential practitioners will tend to be more phenomenologically (Spinelli) or philosophically oriented (van Deurzen) and work, or not, with the immediate therapeutic relation (Cooper, 2003, 2012; M. Craig, et al., 2015). Laing, van Deurzen, Spinelli and Cohn are identified as the key authors in this approach (Cooper, 2003, 2012).

Logotherapy is described by both Cooper $(2003,2012)$ and M. Craig and Colleagues (2015) as a more directive and technique-based practice, which does not place a strong emphasis on the therapeutic relation and will encourage clients to find meaning for their lives from an intersubjective perspective. Frankl and Längle are considered its most influential authors (Cooper, 2012; M. Craig, et al., 2015).

These existential schools are geographically and idiomatically differently distributed worldwide (Correia, et al., 2014), justifying some authors' differentiation of the several existential schools based on geographic and/or linguistic differences (see Besora, 1994; E. Craig, 2008; Jacobsen, 2007).

\section{What Brings the Main Existential Therapies Together?}

Despite the above differences, several authors refer to a few common features that bring together all existential branches. This includes a focus on the actual personal experience of clients (Cooper, 2003, 2012; Cooper, et al., 2011; E. Craig, 2008; Jacobsen, 2007), and using the phenomenological method of enquiry (Barnett \& Madison, 2012; Besora, 1994; E. Craig, 2008; Jacobsen, 2007), while paying attention to an ontic-ontological analysis of clients' way of being-in-the-world (Barnett \& Madison, 2012; Besora, 1994; Cooper, et al., 2011; E. Craig, 2008; Jacobsen, 2007). There is also a shared basis on existential-philosophical assumptions (Besora, 1994; Cooper, 2003, 2012; Cooper, et al., 
2011) and aiming for a more open and authentic relation with the world (Cooper, 2003, 2012;

E. Craig, 2008; Jacobsen, 2007).

\section{Required Research}

From this literature review it is evident that authors agree that a range of different existential therapies exist. However, little has been published concerning what is characteristic and distinctive of each existential therapy and the few claims that have been made are mainly hypothetical, based on each branch's main theoretical constructs or assumptions. Norcross's study (1987) is the single exception of an empirical approach to the differences between branches, but 28 years have passed and his sample was small and limited to a single country and two single branches.

The present paper aims to overcome this gap by looking at the practices of existential therapists from different branches around the globe, and the authors and texts that have most influenced those practices. It considers both the degree to which these branches are different and the specific differences and similarities between them.

\section{Methods}

\section{Design}

A survey study was developed, with data collected through an online questionnaire, built according to Dillman and colleagues' methodology (Dillman, Smyth, \& Christian, 2009; Millar \& Dillman, 2011), to compare different existential practitioners' influences and practices. The survey application took place between March 5 and July 20, 2012.

\section{Participants}


A total of 1,382 participants from all over the world accessed the questionnaire and 1,358 gave their informed consent. There were 1,264 practitioners who considered their therapeutic practice as existential or primarily informed by existential ideas and practices; participants who didn't fall into one of these two categories were excluded. It was not possible to attribute a branch to 255 participants, due to lack of information about their training and affiliated institution and these were also excluded from this study. It was possible to analyse the branches of the remaining 1,009 respondents and this was considered the valid sample for the present paper.

Respondents were from 46 different countries, from all inhabited continents, but mainly from Europe (54.4\%) and Latin-America (26\%). UK $(n=212,21 \%)$ was the most participative country, followed by Austria $(n=147,14.6 \%)$, Brazil $(n=144,14.3 \%)$, Australia $(n=68,6.7 \%)$, the USA $(n=68,6.7 \%)$ and Mexico $(n=56,5.6 \%)-$ for demographics and other participant characteristics' details see Correia and colleagues (2014).

More than half of this sample $(n=573,56.8 \%)$ were trained and/or affiliated to existential-phenomenological institutions (see Table 1). Logotherapy and/or existential analysis contributed with 303 respondents (30\%), existential-humanistic with $82(8.1 \%)$, daseinsanalysis with $29(2.9 \%)$, and $22(2.2 \%)$ participants were trained or affiliated within other psychotherapeutic paradigms (e.g., gestalt, psychoanalytic, person-centered, etc.), but still considered their practice as existential or primarily informed by existential ideas or practices.

(Insert Table 1 here)

\section{Procedures}

\section{Sampling procedures.}


Following the results from the literature review, it was decided to direct this survey only to the most common and consensual four branches of existential psychotherapy: daseinsanalysis, logotherapy, existential-humanistic, and the British school of existential analysis. But, in order to comprise the wider international reality, the British school was included in its umbrella branch: the existential-phenomenological. For the same reason, to accommodate Längle's new developments on Frankl's logotherapy, the term existential analysis was added to the logotherapy branch. In summary, this worldwide survey bases its search and analysis of participants from the following branch division and terminology: daseinsanalysis, the existential-humanistic approach, the existential-phenomenological approach and logotherapy and/or existential analysis.

Following an Internet search, 572 counsellors or psychotherapists were invited directly to participate. From a previous systematic online search of existential institutions across the globe (Correia, et al., 2014), 40 existential therapy institutions were contacted and each agreed to cooperate by sending invitations to their members. It was not possible to accurately calculate the survey response rate, as 14 (35\%) institutions did not provide information about the number of members that they had forwarded invitations to.

\section{Instruments.}

The questionnaire was available in three different languages (English, Portuguese and Spanish). Existential therapists (counsellors and psychotherapists) from all over the world were sent an invitation email, wherein a link directed the interested participant directly to the online survey.

Three list-style, open-ended questions asked participants to name their most influential existential therapy authors and texts and which specific therapeutic methods or practices they consider most characteristic of existential therapy. 
The question about authors was "As an existential/existentially-informed counsellor or psychotherapist, which three authors on existential therapy have most influenced your practice?" and participants were asked to complete up to three open-ended answer boxes labelled: "Author 1", "Author 2", and "Author 3". The question about texts asked "As an existential/existentially-informed counsellor or psychotherapist, which three specific texts (book, book chapter, or journal article) on existential therapy have most influenced your practice?" and participants were invited to complete up to three pairs of open-ended answer boxes, labelled "Author 1/Text 1", "Author 2/Text 2", "Author3/Text 3". The question about practices was "As an existential/existentially-informed counsellor or psychotherapist, which three specific therapeutic methods or practices would you consider most characteristic of existential therapy?" and participants were asked to complete up to three open-ended answer boxes labelled: "Practice 1", "Practice 2", and "Practice 3".

These questions were part of a larger survey and were, respectively, number seven, nine and eight of a 10-item questionnaire, designed to study the practices, influences and characteristics of existential counsellors and psychotherapists around the globe (see, Correia, et al., 2014; Correia, Cooper, \& Berdondini, 2015; Correia, Cooper, Berdondini, \& Correia, 2015).

\section{Analysis.}

Participants' branches were identified based on their training and affiliation institutions (questions 2a and 5a, respectively): they were attributed to the branch of their training and affiliation institutions. Whenever these branches did not match, prevalence was given to the societies the participants were affiliated to. The branches of existential institutions were identified, initially, by the name (for example, the "Instituto Peruano de Logoterapia, Viktor Frankl”). Whenever this was not self-evident, an email was sent to the 
institution to clarify their branch ( 29 emails were sent to clarify this information). For the 14 institutions that did not respond, a careful reading of their website was made to identify their branch. A total of 128 existential therapy institutions and their respective branches were identified (see, Correia, et al., 2014).

Participants' responses to authors and texts questions were written in different languages and in many different ways. To enable statistical analysis, responses were normalized and codified into numeric codes. As the questions specifically ask for authors and texts from existential therapy, all existential philosophy or other non-therapy responses were excluded from the present analysis.

Responses to the question about the most characteristic existential practices were analysed and codified using thematic analysis. Braun \& Clarke's (2006) six steps methodology was used, following an inductive (data-driven) analysis and based on a semantic approach. The analysis was performed independently by two analysts $\left(1^{\text {st }}\right.$ and $4^{\text {th }}$ author) and two reviewers ( $2^{\text {nd }}$ and $3^{\text {rd }}$ author): one analyst and one reviewer are existential therapists, while the other is from another therapeutic paradigm (for detailed analysis procedure see Correia, Cooper, Berdondini, et al., 2015).

A total of 88 different practices (the code level) were identified and then clustered into 20 sub-themes and seven overarching themes of practice. For this paper, the analysis was focus on the themes and main sub-themes of practice chosen by participants of each branch. Some responses were too general (e.g., "Daseinsanalysis" or "Logotherapy”) or nonspecific (e.g., "therapeutic" or "transcendentalism") to tell us of a concrete therapeutic practice. These responses were grouped into two overarching themes: Generic reference to existential or humanistic psychotherapy models and Nonspecific, respectively, and will not be considered for statistical analysis. 
Responses were downloaded from the online platform to an SPSS database, where data codification and statistical descriptive and inferential analysis were conducted.

A chi-square test was performed over the different thematised answers given by participants to determine if practitioners' responses to most characteristic practices were homogeneous among different branches. To clarify and quantify the differences, a logistic regression analysis was conducted. To perform this probabilistic statistical model participant answers (dependent variable) were transformed into binary variables. Logistic regression does not consider how many times a practitioner referred to a certain practice, but only if he/she referred or not (one yes or one no) to that theme of practice. As some participants gave more than one answer concerning the same theme of practice, some accuracy may have been lost in this attempt to quantify and determine the specific differences among branches.

\section{Results}

\section{Most Influential Authors}

Daseinsanalytic participants gave 46 valid responses, citing 17 different authors to the most influential author's question. Boss was their most frequent response $(n=19,41.3 \%$ of responses from daseinanalysts, see Table 2). Binswanger was the second most common choice $(n=7,15.2 \%)$, followed by the Brazilian daseinsanalyst Spanoudis $(n=4,8.7 \%)$. An existential-humanistic (May) and an existential-phenomenological (Spinelli) associated author were both chosen twice (4.3\%). Frankl was chosen a single time $(2.2 \%)$, the only logotherapist cited by the daseinsanalysts.

Participants associated with the existential-humanistic branch gave 194 valid choices and 34 different influential authors. Yalom $(n=31,16 \%)$ was their most influential (see Table 2), followed by May $(n=28,14.4 \%)$ and Frankl $(n=19,9.8 \%)$. Frankl was the sole 
logotherapy author considered influential by the existential-humanistic sample. Spinelli $(n=$ $13,6.7 \%)$ and van Deurzen $(n=8,4.1 \%)$, existential-phenomenological associated authors both, were considered the $6^{\text {th }}$ and $7^{\text {th }}$ most influential, and Boss, a daseinsanalytic author, was the $11^{\text {th }}$ most influential $(n=6,3.1 \%)$ to their therapeutic practice.

(Insert Table 2 here)

Spinelli was the most influential author for the existential-phenomenological sample (see Table 2), with $215(19.3 \%)$ of the 1,113 validated responses. This was followed very closely by Yalom $(n=213,19.1 \%)$, and then van Deurzen $(n=198,17.8 \%)$. Frankl came next $(n=73,6.6 \%)$, with less than half the frequency of van Deurzen, and was the only logotherapy author considered influential among the 75 different authors named by the existential-phenomenological associated participants. Their most influential daseinsanalyst author was Boss, the $9^{\text {th }}$ most influential $(n=18,1.6 \%)$.

Within the 63 different influential authors chosen by the logotherapy and/or existential analysis participants, Frankl $(n=267,35.7 \%)$ and Längle $(n=203,27.1 \%)$ add up to $62.8 \%$ (see Table 2$)$ of the 748 validated answers. Yalom $(n=76,10.2 \%)$ was their $3^{\text {rd }}$ most influential author. The existential-phenomenological author most influential to logotherapy participants' practice was van Deurzen, the $7^{\text {th }}$ of their rank $(n=8,1.1 \%)$. Binswanger, the $10^{\text {th }}(n=6,0.8 \%)$, was the most influential from the daseinsanalytic branch.

The large number of different authors, and the visible differences among branches made inductive statistics not viable to compare existential therapies' differences for this question.

\section{Most Influential Texts}


Participants associated to the daseinsanalytic branch gave 48 valid responses to the question of the most influential text, the most common being Boss's Existential foundation of medicine and psychology $(n=9,18.8 \%)$, cited almost twice more than Heidegger's Zollikon seminars $(n=5,10.4 \%)$. Three books came third $(n=4,8.3 \%)$, one from Binswanger and two from Boss (see Table 3). The five most influential texts $(n=26,54.2 \%)$ are all associated to the daseinsanalytic branch. No logotherapy text was found among their 23 different choices, and two books from the British school were chosen once.

Practitioners associated to the existential humanistic branch gave 171 validated answers and 67 different texts. Frankl's Man's search for meaning $(n=16,9.4 \%)$ and Yalom's Existential psychotherapy $(n=15,8.8 \%)$, were their most influential texts (see Table 3). Bugental's Psychotherapy isn't what you think and Schneider's Existentialintegrative psychotherapy came third, both representing $4.7 \%$ of existential-humanistic responses $(n=8)$. With the exception of Frankl's Man's search for meaning, the eight most influential texts are all from the USA $(n=52,30.4 \%)$. Frankl's text was also an exception of logotherapy's influence among existential-humanistic participants, as only one other Frankl text (The doctor and the soul) was chosen a single time $(0.6 \%)$.

(Insert Table 3 here)

Existential-phenomenological participants gave 185 different texts in 944 validated answers. Yalom's Existential psychotherapy $(n=108,11.4 \%)$ was their most influential text. Van Deurzen's Everyday mysteries $(n=60,6.4 \%)$ and Spinelli's Practising existential psychotherapy ( $n=58,6.1 \%$ ) came second and third, respectively (see Table 3). Frankl's Man's search for meaning was their $6^{\text {th }}$ most influential text $(n=45,4.8 \%)$, but the next logotherapy text, Frankl's The doctor and the soul, appears as the $42^{\text {nd }}$ most influential text ( $n$ 
$=3,0.3 \%)$. Zollikon seminars, the $26^{\text {th }}$ most influential $(n=6,0.6 \%)$, was the daseinsanalytic associated book that most influenced the practice of existentialphenomenological practitioners.

Participants associated to the logotherapy and/or existential analysis branch gave 574 validated responses and 128 different texts. Two of Frankl's books were their most influential texts: Man's search for meaning $(n=104,18.1 \%)$ and The doctor and the soul $(n$ $=59,10.3 \%)$. Längle's Sinnvoll leben $(n=36,6.3 \%)$ was their third most influential text

(see Table 3). With the exception of Yalom's Existential psychotherapy $(n=33,5.7 \%)$, the 11 most influential texts are all from Frankl and Längle $(n=311,54.2 \%)$, two logotherapy and/or existential analysis associated authors. The most influential existentialphenomenological associated text was van Deurzen's Existential Counselling \& Psychotherapy in Practice, ranking the $23^{\text {rd }}$ most influential $(n=3,0.5 \%)$ while a single daseinsanalytic text was considered influential by a single participant $(n=1,0.2 \%)$ : Binswanger's Trois formes manquées de la présence humaine.

For the texts question, inferential analysis was again not possible due to the large number of different texts and the visible differences among branches.

\section{Most Characteristic Practices}

Participants associated to the daseinsanalytic branch gave 34 considered responses. Phenomenological practices (see Table 4) was the most frequent theme $(n=16,47.1 \%)$ in daseinsanalysts' answers to existential therapy's most characteristic practices: in particular, the use of the Phenomenological method of enquiry $(n=9,26.5 \%)$ and Hermeneutic based practices $(n=6,17.6 \%)$. With less than half as many citations, Practices informed by existential assumptions $(n=7,20.6 \%)$ was their second most popular theme of practice, referring to either the exploration of clients' relation with the existential givens $(n=3,8.8 \%)$ 
or Addressing other existential assumptions $(n=4,11.8 \%)$ in therapy, such as "Detecting the ontological" P.796. The Relational practices theme comprised $17.6 \%(n=6)$ of daseinsanalysts' responses, in particular the importance of adopting a Relational stance $(n=$ $3,8.8 \%)$ or Person-centered related attitudes, like Empathy $(n=2,5.9 \%)$. The use of methods associated to other therapeutic paradigms represented $11.8 \%(n=4)$ and a single participant $(2.9 \%)$ referred to the search for the meaning of life, an intervention associated logotherapy.

The existential-humanistic sample gave 161 coded practices considered for statistical analysis. Relational practices (see Table 4 ) was their most frequent theme $(n=48,29.8 \%)$, in particular the importance of a relational stance $(n=24,14.9 \%)$. Within the relational practices, "Identifying here and now windows for open dialog" P.1054, i.e., Working in the here-and-now, was their most frequent code of response $(n=12,7.5 \%)$. Practices informed by existential assumptions was their second most frequent theme $(n=42,26.1 \%)$ particularly for Addressing the existential givens ( $n=24,14.9 \%)$, especially Freedom/choice/responsibility. The use of practices or methods usually related with other therapeutic paradigms was existential-humanistic's third most important theme of practice ( $n$ $=32,19.9 \%$ ) and, within this theme, Experiential and body practices was the most frequent sub-theme $(n=18,11.2 \%)$. Only then came the phenomenological practices theme $(n=31$, $19.3 \%)$, mainly the use of the phenomenological method $(n=23,14.3 \%)$. No references were made to hermeneutics. The use of Methods associated with specific existential branches represent no more than 5\% $(n=8)$ of existential-humanistic responses.

(Insert Table 4 here) 
Existential-phenomenological associated participants gave 1,315 considered answers. The phenomenological practices' theme was the most frequent among existentialphenomenological participants $(n=475,36.1 \%)$, mainly through references to the use of "The phenomenological questioning method" P.748 ( $n=370,28.1 \%)$ : see the Phenomenological method sub-theme (Table 4). Practices informed by existential assumptions was their second most frequent theme $(n=389,29.6 \%)$, and addressing the existential givens $(n=213,16.2 \%)$, in particular Freedom/choice/responsibility $(n=53,4 \%)$, was more frequent than addressing other existential assumptions $(n=157,11.9 \%)$, like Exploring/understanding client's worldview $(n=44,3.3 \%)$. Relational practices were existential-phenomenological participants' third most frequent theme ( $n=287,21.8 \%)$, and relevance was given to adopting a relational stance $(n=147,11.2 \%)$. Practices of other therapeutic paradigms represented $8.3 \%(n=109)$ - in particular experiential and body practices $(n=42,3.2 \%)$ - and methods associated with specific existential schools comprised $4.2 \%(n=55)$ of their coded responses.

Logotherapy and/or existential analysis associated participants gave 652 responses validated for statistical analysis. Methods associated with classic logotherapy, and Längle's existential analysis, were considered the most characteristic methods of existential therapy ( $n$ $=474,72.7 \%$ ), according to participants from this particular branch (see Logotherapy and existential analysis methods sub-theme, Table 4). Within their 14 most frequent codes of practice, all were specific logotherapy or existential analysis methods - e.g., Personal existential analysis method $(n=147,22.5 \%)$, Paradoxical intention $(n=59,9 \%)$, Dereflexion $(n=41,6.3 \%)$, Personal position finding method $(n=36,5.5 \%)$ and Addressing the four fundamental motivations ( $n=36,5.5 \%)$ - with the single exception for the application of the phenomenological method, which was their third most characteristic specific practice $(n=58,8.9 \%)$. Phenomenological practices, their second most frequent 
theme, represented no more than $11.2 \%(n=73)$ and the third theme, relational practices, $6.4 \%(n=42)$. The practices informed by existential assumptions were referred to 37 times (5.7\%) and the use of techniques from other non-existential psychotherapeutic paradigms represented $3.8 \%(n=25)$.

\section{Inferential statistics.}

Chi-square test applied to the thematised answers.

A chi-square test of homogeneity was conducted to determine whether participants' understanding of existential therapy's most characteristic practices are equally distributed among branches. Results show that the frequency of the chosen themes differed significantly depending upon the participant's branch $X^{2}(12 ; n=2,162)=1,198.522 ; p<.001$.

\section{Logistic regression applied to the participants' dichotomized answers.}

To determine and quantify the differences between branches, logistic regression analyses were conducted. This predicts the likelihood (odds ratio) of a practitioner of a certain branch choosing one of the themes of practice (as the most characteristic of existential therapy), when compared with a practitioner from another branch (reference category).

The model's chi-square statistics confirm that the independent variables (branches), as a whole, significantly affect each of the dichotomized dependent variables (thematised practice): Phenomenological practices $X^{2}(3)=150.646 ; p<.001$; Practices informed by existential assumptions $X^{2}(3)=128.106 ; p<.001$; Relational practices $X^{2}(3)=82.336$; $p<$ .001 ; Methods associated with specific existential branches $X^{2}(3)=461.745 ; p<.001$; Practices of other therapeutic paradigms $X^{2}(3)=25.504 ; p<.001$.

The adjusted models show that a daseinsanalyst (see Table 5) is almost three times more likely to choose a phenomenological practice $\left(\mathrm{OR}=2.763\right.$; Wald's $X^{2}(1)=4.335 ; p=$ 
.037), as the most characteristic of existential therapy, than an existential-humanistic (reference category), but 70\% less likely to choose a practice informed by existential assumptions $\left(\mathrm{OR}=0.299\right.$; Wald's $\left.X^{2}(1)=4.080 ; p=.043\right)$. Compared with an existentialphenomenological therapist, a daseinsanalyst is $75.6 \%$ less likely to choose a practice informed by existential assumptions $\left(\mathrm{OR}=0.244\right.$; Wald's $\left.X^{2}(1)=6.47 ; p=.011\right)$ and $70.6 \%$ less likely to choose a relational practice $\left(\mathrm{OR}=0.294\right.$; Wald's $\left.X^{2}(1)=4.811 ; p=.028\right)$. Compared with a logotherapist, the odds of a daseinsanalyst choosing a phenomenological practice will be 3.6 times bigger $\left(\mathrm{OR}=3.671\right.$; Wald's $\left.X^{2}(1)=8.59 ; p=.003\right)$, but only one daseinsanalyst chose a method associated with specific existential branches.

(Insert Table 5 here)

The odds of an existential-humanistic choosing a practice from another therapeutic paradigm as the most characteristic of the existential practice is two times bigger $(\mathrm{OR}=$ 2.056; Wald's $\left.X^{2}(1)=6.963 ; p=.008\right)$ than that of an existential-phenomenological practitioner (see Table 5). But the latter is almost five times more likely to choose a phenomenological practice $\left(\mathrm{OR}=4.968\right.$; Wald's $\left.X^{2}(1)=36.232 ; p<.001\right)$ when compared to the former. Except for phenomenological practices, existential-humanist and logotherapist odds ratios are significantly different for all thematised practices: The odds of choosing relational practices and practices related to other therapeutic paradigms are almost five times bigger for an existential humanistic $\left(\mathrm{OR}=4.925\right.$; Wald's $X^{2}(1)=27.573 ; p<.001$ and $\mathrm{OR}=$ 4.849; Wald's $X^{2}(1)=22.874 ; p<.001$, respectively) and 7.2 times bigger for practices informed by existential assumptions $\left(\mathrm{OR}=7.26\right.$; Wald's $\left.X^{2}(1)=38.271 ; p<.001\right)$. On the other hand, logotherapists are 43 times more likely to choose their own specific methods (OR $=43.47 ;$ Wald's $\left.X^{2}(1)=84.532 ; p<.001\right)$. 
The existential-phenomenological odds ratio of choosing existential therapy's most characteristic practices is significantly different for all themes of practice, when compared with a logotherapy and/or existential analysis practitioner (see Table 5): The existentialphenomenological practitioner will be 2.3 times more likely to choose a practice of another therapeutic paradigm $\left(\mathrm{OR}=2.358\right.$; Wald's $\left.X^{2}(1)=6.963 ; p=.008\right) ; 5.2$ times more likely to choose a relational practice $\left(\mathrm{OR}=5.284\right.$; Wald's $\left.X^{2}(1)=61.646 ; p<.001\right) ; 6.6$ times more likely to choose a phenomenological practice $\left(\mathrm{OR}=6.601\right.$; Wald's $X^{2}(1)=120.482 ; p<$ .001 ); and almost nine times more likely to refer to practices informed by existential assumptions $\left(\mathrm{OR}=8.905\right.$; Wald's $\left.X^{2}(1)=85.623 ; p<.001\right)$. Moreover, the odds of choosing a method associated with specific existential branches is 46 times bigger $(\mathrm{OR}=$ 46.091; Wald's $\left.X^{2}(1)=289.714 ; p<.001\right)$ for a logotherapist, when compared with an existential-phenomenological therapist.

\section{Discussion}

Data from both self-reported influences and practices suggests differences and some similarities among the four main existential branches. Practitioners' most influential authors and texts are usually related to the branch of their training or affiliation institutions. Five overarching themes of practice were found in common but, depending on their training or affiliation branch, practitioners place a different relevance on each of those characteristic practices.

\section{Differences}

\section{Influences.}


Data shows that among existential therapists, the scope of influence of an author is pretty much limited to the branch he is related to. This is particularly so with logotherapists, who reported being both influenced mainly by its own authors and texts and having little influence (except for Frankl) on other branches. Längle, for instance, was considered a great influence among logotherapists' practice but not a single reference to his name or work was made among participants from other alignments.

These findings were consistent with the literature review about branches' most influential authors and gives emphasis to the specificities of each branch influence.

\section{Practices.}

Five themes of practice are shared among the main existential branches, but the frequency with which each of those practices are considered the most characteristic of existential therapy differs significantly depending on respondents' training or affiliated branch. Daseinsanalysis, existential-humanistic and the existential-phenomenological understanding of existential therapy's most characteristic practices show significant differences with each other concerning the choice of two themes of practice (see Table 5). Logotherapy and/or existential analysis, on the other hand, presented two or more significant and pronounced differences with all other branches, in particular with the existentialphenomenological.

Daseinsanalysts presented a similar theme ranking to the existentialphenomenological participants (see Table 4). Phenomenological practices were their main theme of existential practice and a particular relevance (not found with any other branch) was given to hermeneutic interventions. Rogerian relational practices were as important to daseinsanalysts as they were to existential-humanistic, but no mention was made of addressing what is happening in the therapeutic relation, as both the existential-humanistic 
and existential-phenomenological respondents had. Not a single allusion to psychoanalytic specific techniques was found. These findings corroborate E. Craig (2008) and Besora's (1994) claim of a phenomenological and hermeneutic perspective upon clients' problems, but do not corroborate Norcross' (1987) results of a more psychoanalytic and less Rogerian oriented approach. In summary, daseinsanalysts mentioned a practice based on the phenomenological method of enquiry and on a hermeneutic-analytical stance towards clients' problems: "The phenomenological analysis asks, as its natural continuity, for an Existential Analysis" (Besora, 1994, p. 19). A good therapeutic relation, based on attitudes like presence, was considered characteristic of an existential practice, but no relevance was given to the here-and-now work within the immediate therapeutic relation.

Existential-humanistics respondents gave greater emphasis to relational over phenomenological practices and existential assumptions. They frequently indicated practices from other therapeutic paradigms, in particular experiential and body practices. Here-andnow interventions and exploring feelings and emotions, were their first and fifth most coded practices, while not a single allusion was made to hermeneutic interventions. These results are consistent with Besora's (1994) and E. Craig's (2008) statements that existentialhumanistic psychotherapists are more focused on the phenomenal experience of the here-andnow, ignoring a more historical-analytical perspective of clients. The relational depth of the therapeutic relation was frequently present in existential-humanistic practitioners' responses to answers like "Presence" or "Encounter". Existential-humanistic practitioners reported practices that point to a more relational, phenomenal and experiential therapy than their counterparts.

Existential-phenomenological responses can corroborate some of both Cooper's (2003, 2012) and Craig et al.'s (2015) assertions about the British school of existential analysis. The relevance attributed to both the phenomenological method of enquiry and to 
phenomenological based attitudes and practices can corroborate the idea of a phenomenological, descriptive, non-directive and non-pathologising perspective (Cooper, 2003, 2012; M. Craig, et al., 2015). Both a phenomenological (Spinelli) and a philosophically (van Deurzen) based therapy are referred to in our findings (and one kind of practice does not necessarily exclude the other, as $45.4 \%$ of participants chose both practices simultaneously). Working in the here-and-now (work with the immediate therapeutic relation) and exploring/understanding clients' worldviews (inter-worldly) were existentialphenomenological practitioners' fifth and sixth most frequent specific practices. Existentialphenomenological data suggests a practice based on the phenomenological method of enquiry with a focus on helping the clients to explore and/or acknowledge the impact and relation with particular existential-philosophical assumptions/presuppositions. Instead of a hermeneutic-analytical stance (as with daseinsanalysis), a more descriptive and relational perspective of therapy was given.

Logotherapists had a different perspective on existential therapy's most characteristic practices (see Tables 4 and 5). Logotherapy and existential analysis' specific methods represented $72.7 \%$ of all logotherapists' coded practices, while those same methods accounted for no more than $4.3 \%$ to respondents of other existential branches. Of all the 548 responses referring to logotherapy and existential analysis methods, $474(87.2 \%)$ were given by therapists trained and/or affiliated to logotherapy and/or existential analysis institutions. A great emphasis was given to both their classical (e.g., paradoxical intention, dereflexion) and more recent step-wise methods (e.g., personal existential analysis method, personal position finding method). In addition, relational practices represented no more than $6.4 \%$ of their coded practices, corroborating both Cooper $(2003,2012)$ and M. Craig and Colleagues' (2015) description of a more directive and technique-based practice, with less emphasis on the therapeutic relation. Logotherapists gave some relevance to the phenomenological 
method of enquiry - and Längle (Längle, 2003, 2012, 2013) states that phenomenology underpins all his step-wise methods - but their understanding of the existential practice relies mainly on their own specific techniques. As relational practices, existential assumptions were not as relevant as they are to all other branches, and finding personal meaning was their main therapeutic goal.

\section{Similaraties}

\section{Influences.}

Frank1, May, Binswanger, Bugental and Spinelli were the few authors considered influential by participants of all four branches. Yalom's Existential psychotherapy, May, Angel and Ellenberger's Existence and Bugental's The Art of the Psychotherapist were the only texts referred to as influential by participants of all main branches. Data from both authors and texts highlights Frankl and Yalom as existential therapies' most influential authors across all branches.

\section{Practices.}

Among daseinsanalysts, existential-humanistic and existential-phenomenological it was not found significant differences on the odds for choosing three of the five overarching themes of practice (see Table 5).

Despite the differences that were identified, phenomenological practice was the most shared theme among respondents from all branches, in particular the use of the phenomenological method (focus on the phenomena as it shows itself) to enquiry, question, describing or exploring a particular subject with the client (see Table 4). This is even more evident if it is consider that almost half $(n=264 ; 10.8 \%)$ of the logotherapy and existential 
analysis methods, cited by the logotherapists, were references to the several step-wised (but still) phenomenological-based methods developed by Längle (2013).

Theoretical claims that phenomenology (Barnett \& Madison, 2012; Besora, 1994; E. Craig, 2008; Jacobsen, 2007) and the sharing of a few existential-philosophical assumptions (Besora, 1994; Cooper, 2003, 2012; Cooper, et al., 2011) are a common feature among existential therapies, found some empirical support here. Practitioners from all four branches referred also to relational practices and all of them referred to the application of several different methods or practices, either from other therapeutic paradigms or from specific existential schools.

\section{Limitations}

Data concerns practitioners' self-reported perceived influences and practices, which may not represent what really influenced them and what they really practice.

Respondents were not asked directly to which branch they identify their existential practice. Despite the problems associated with self-reported answers, this could have been a more accurate way of determining the participants' branch: The fact that a participant was trained or is a member of certain institution may not always mean that their main influences and practices represent those associated with their institutional branch. Hence, those who responded to the questionnaire may not be representative of the existential branch they are associated with.

The number of participants associated to the daseinsanalytic branch was clearly low, adding some limitations on branch representativeness and statistical power.

\section{Implications for Practice and Further Research}


Despite the limitations above, this data gives empirical evidence about the similarities and differences among practitioners from the four main existential branches. Data about practitioners' self-reported most influential authors and texts and practitioners' perspectives on what they consider to be existential therapy's most characteristic practices helps to clarify the particularities and complexity of existential psychotherapy.

Recognizing differences and similarities can be a first step towards acknowledging and respecting what separates and what unites existential therapies. Data seems to convey exchange difficulties, in particular, between logotherapy and/or existential analysis and its counterparts.

Future research should focus on actual therapy sessions, to verify if self-reported differences are confirmed by different in-session practices.

\section{Conclusion}

In a previous paper (Correia, et al., 2014), it was shown that the four main existential therapy branches are geographically and idiomatically differently distributed worldwide: Daseinsanalysis is mainly concentrated in the German-speaking countries of central Europe and in Brazil; the existential-humanistic branch is largely confined to the USA, recently reaching China; the existential-phenomenological branch is a more culturally and linguistically diverse branch, with no expression in German speaking countries; Logotherapy is mainly concentrated in German-speaking European countries and in Spanish-speaking Latin-American countries. Here, strong evidence is presented corroborating differences on both self-reported influences and practices among therapists associated to those same branches. 
May, Binswanger, Bugental and Spinelli, but mainly Frankl and Yalom, are the few shared authorial influences among the four main branches, while the rule of each approach's own authors as their main influences prevails.

The application of the phenomenological method is what most unifies the different branches' understanding about existential therapy's most characteristic practices. The relevance of existential-philosophical assumptions and the relational attention on practice are also shared beliefs, mainly between daseinsanalysts, existential-phenomenological and existential-humanistic practitioners. Logotherapists' understanding of the existential practice relies mostly on their own very specific practices, barely referred to by their counterparts.

Logotherapy and/or existential analysis presented itself in this study as a more idiosyncratic and technique-based existential psychotherapy; existential-humanistic branch is characterized as a more relational, experiential and eclectic approach according to its selfreported practices; daseinsanalysis and the existential-phenomenological reveal themselves as closely related branches: the first more hermeneutic-analytical, the second more relational and descriptive.

Present study has contributed to an empirically based characterization and understanding of existential therapies' differences and similarities. It is now easier 'to delineate a movement which is multiple in source and influence at the same time that it is one identifiable force” (Halling \& Nill, 1995, p. 1)

\section{References}

Barnett, L., \& Madison, G. (Eds.). (2012). Existential therapy: Legacy, vibrancy and dialogue. London: Routledge. 
Basescu, S. (1963). Existential therapy. In A. Deutsch \& H. Fishman (Eds.), The encyclopedia of mental health (Vol. 2, pp. 583-595). New York: Franklin Watts.

Besora, M. V. (1994). Las psicoterapias existenciales: Desarollo historico y modalidades conceptuales. In J. A. C. Teixeira (Ed.), Fenomenologia e psicologia (pp. 11-23). Lisboa: ISPA.

Braun, V., \& Clarke, V. (2006). Using thematic analysis in psychology. Qualitative Research in Psychology, 3(2), 77-101. doi: 10.1191/1478088706qp063oa

Burston, D. (2003). Existentialism, humanism and psychotherapy. [Article]. Existential Analysis: Journal of the Society for Existential Analysis, 14(2), 309.

Cooper, M. (2003). Existential therapies. London: Sage Publications.

Cooper, M. (2012). The existential counselling primer: A concise, accessible and comprehensive introduction. Ross-on-Wye: PCCS.

Cooper, M., Vos, J., \& Craig, M. (2011). Protocol for EXIST review. Glasgow: University of Stratchlyde.

Correia, E. A., Cooper, M., \& Berdondini, L. (2014). The worldwide distribution and characteristics of existential counsellors and psychotherapists. Existential Analysis, 25(2), 321-337.

Correia, E. A., Cooper, M., \& Berdondini, L. (2015). Existential psychotherapy: An international survey of the key authors and texts influencing practice. Journal of Contemporary Psychotherapy, 45(1), 3-10. doi: 10.1007/s10879-014-9275-y

Correia, E. A., Cooper, M., Berdondini, L., \& Correia, K. (2015). Characteristic practices of existential psychotherapy: A worldwide survey of practitioners' perspectives. Manuscript submitted for publication.

Craig, E. (2008). A brief overview of existential depth psychotherapy. Humanistic Psychologist, 36(3/4), 211-226. doi: 10.1080/08873260802349958

Craig, M., Vos, J., Cooper, M., \& Correia, E. (2015). Existential psychotherapies. In D. J. Cain, K. Keenan \& S. Rubin (Eds.), Humanistic psychotherapies: Handbook of research and practice (2 ed.): American Psychological Association.

Deurzen, E. v., \& Adams, M. (2011). Skills in existential counselling \& psychotherapy. London: Sage Publications.

Dillman, D. A., Smyth, J. D., \& Christian, L. M. (2009). Internet, mail, and mixed-mode surveys: The tailored design method (3rd ed.). Hoboken: John Wiley \& Sons.

Groth, M. (2015). ET, phone home. Hermeneutic Circular(October), 18-19. 
Halling, S., \& Nill, J. D. (1995). A brief history of existential-phenomenological psychiatry and psychotherapy. Journal of Phenomenological Psychology, 26(1), 1-45. doi: $10.1163 / 156916295 \times 00024$

Hoffman, L. (2007). Chapter 6: Existential-Integrative Psychotherapy and God Image. Journal of Spirituality in Mental Health, 9(3/4), 105-137. doi: 10.1300/J515v09n0306

Jacobsen, B. (2007). Invitation to existential psychology: A psychology for the unique human being and its applications in therapy. Chichester: John Wiley \& Sons.

Längle, A. (2003). The method of "personal existential analysis". European Psychotherapy, $4(1), 59-75$.

Längle, A. (2012). The viennese school of existential analysis: The search for meaning and affirmation of life. In L. Barnett \& G. Madison (Eds.), Existential therapy: Legacy, vibrancy and dialogue (pp. 159-170). London: Routledge.

Längle, A. (2013). Lehrbuch zur existenzanalyse: Grundlagen. Wien: Facultas.wuv.

Mahrer, A. R. (1996). Existential-humanistic psychotherapy and the religious person. In E. P. Shafranske (Ed.), Religion and the clinical practice of psychology. (pp. 433-460). Washington, DC US: American Psychological Association.

Millar, M. M., \& Dillman, D. A. (2011). Improving response to web and mixed-mode surveys. Public Opinion Quarterly, 75(2), 249-269.

Norcross, J. C. (1987). A rational and empirical analysis of existential psychotherapy. Journal of Humanistic Psychology, 27(1), 41-68. doi: 10.1177/0022167887271005

Owen, I. R. (1994). Introducing an existential-phenomenological approach Part II: Theory for practice. Counselling Psychology Quarterly, 7(4), 347-358.

Schneider, K. J., \& Krug, O. T. (2010). Existential-humanistic therapy. Washington, DC: American Psychological Association.

Teixeira, J. A. C. (2006). Introdução à psicoterapia existencial. Análise Psicológica, 24(3), 289-309.

Walsh, R. A., \& McElwain, B. (2002). Existential psychotherapies. In D. J. Cain (Ed.), Humanistic psychotherapies: Handbook of research and practice. (pp. 253-278). Washington, DC US: American Psychological Association.

Yalom, I. D. (1980). Existential psychotherapy. New York: Basic Books. 